\title{
Multivariate Assessment of Marginal Fit Concerning Two Types of Dental Inlays Obtained Through Two CAD-CAM Technology Scanning Methods - an in vitro Follow-up Study
}

\begin{abstract}
MARIUS NEGUCIOIU', DANIELA POPA*, DANIELA CONDOR², CRISTIAN CULCITCHI', DOINA PRODAN³, MARIOARA MOLDOVAN ${ }^{3}$, SMARANDA BUDURU ${ }^{1}$

${ }^{1}$ Iuliu Hatieganu University of Medicine and Pharmacy, Department of Prosthodontics, 32 Clinicilor Str., 400006, Cluj-Napoca, Romania

${ }^{2}$ Iuliu Hatieganu University of Medicine and Pharmacy, Department of Periodontology, 15 Babes Str., 400006, Cluj-Napoca, Romania

${ }^{3}$ Babes Bolyai University, Raluca Ripan Chemistry Research Institute, Department of Polymer Composites, 30 Fantanele Str., 400294, Cluj-Napoca, Romania

Our aim in this follow-up in vitro study was to compare differences in marginal fit of inlays fabricated by CAD/CAM technique, using 2 different types of materials (one type of ceramic and one type of hybrid ceramic) and 2 different types of scanning: intraoral scanning (we use quotation marks because of the lack of a true intraoral environment) and model scanning, both performed on a Frasaco Typodontmodel. Marginal fit measurement was carried out with an electronic microscope at 1000x magnification. Our results proved to be better in the case of the ceramic we used, while model scanning proved to be more accurate than intraoral scanning. The best combination we obtained in terms of marginal fit was found when using ceramic and model scanning.
\end{abstract}

Keywords:marginal fit, intraoral scanning, model scanning, ceramic, hybrid ceramic, SEM, Vita Enamic, IPS Empress CAD.

Obtaining a model of good quality that true to its original is extremely important for the success of the treatment; different types of materials and impression techniques have been used over the years to achieve this desired accuracy [1]. Since the introduction of dental CAD/CAM systems, the adaptation of restorations may be improved by combining intraoral scanning and digital milling $[2,3]$.

Marginal fit, or marginal adaptation as it is sometimes referred to, is also crucial for ceramic inlay restorations in order to avoid resin cement wear and plaque accumulation. Marginal gap formation at the toothrestoration interface exposes resin cement to the oral environment, easily leading to cement wear. Marginal discrepancies cause debris and food to act as potential irritants, which might induce gingival inflammation, secondary caries and later on even devitalization of the pulp [4].

The adaptation of a restoration is determined by measuring its marginal and internal gaps, which are important factors for the long-term clinical success [5-10].

Intraoral digital scanners have brought dentistry into a full digital era. Performing intraoral scans may increase efficiency due to several factors. Impression trays and materials, which have to be cleaned, disinfected and then shipped to laboratory, are no longer required. The electronic files can be digitally sent and stored, saving time, costs, and improving space management. Distortion as well as volumetric variations related to classic impression materials and cast stone properties are eliminated, simultaneously improving patient acceptance [11, 12].

The performance of indirect composite and ceramic restorations, generated either chair-side (i.e. CAD/CAM) or in a dental laboratory, is well documented. There have been significant improvements in software management of function and anatomy, thus explaining their increasing current usage [13].
Despite this, however, studies regarding the accuracy digital systems are still only available in limited amounts [14].

The aim of our follow-up in vitro study was to continue the evaluation and comparison of the marginal adaptation of inlay restorations fabricated by CAD/CAM systems, scanned with two different scanners (the 3Shape TRIOS 3 intraoral scanner and the 3Shape E3 Lab scanner, both produced by 3Shape, Copenhagen, Denmark) and fabricated with two innovative materials (Enamic $\AA$ hybrid ceramic, Vita, Germany, and IPS Empress CAD ceramic, Ivoclar Vivadent, Liechtenstein).

\section{Experimental part}

Materials and methods

A preparation for a mesio-occluso-disto-ligual inlay was carried out on tooth 3.7 (according to the IDF classification) of a AG-3 Standard Restorative Typodont (Frasaco, USA) model. The preparation was extended on 4 distinctsurfaces in order to obtain a more complex cavity shape, therefore raising the challenge for optimal scanning and milling. The preparation, along with the entire lower arch, the upper arch and the occlusion were first scanned (scan S1) with the TRIOS 3 intraoral scanner (3Shape, Copenhagen, Denmark). The scan files were then sent to the dental laboratory via the local network (Fig. 1). Later on, both arches of the Frasaco Typodont were sent to the dental laboratory in order to be scanned (scan S2) using the 3Shape E3 Lab Scanner (3Shape, Copenhagen, Denmark) (Fig. 2).

From the 2 scans we obtained 2 virtual models ( $M 1$ and M2) which were used by the same operator to design 3 virtual inlays for each material using the same design parameters. In the end, 12 inlays were obtained through milling with the Zenotec Select Hybrid milling machine 


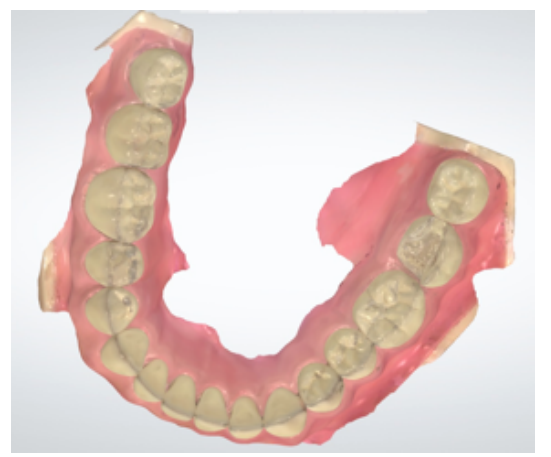

Fig. 1. Intraoral scan

(S1).

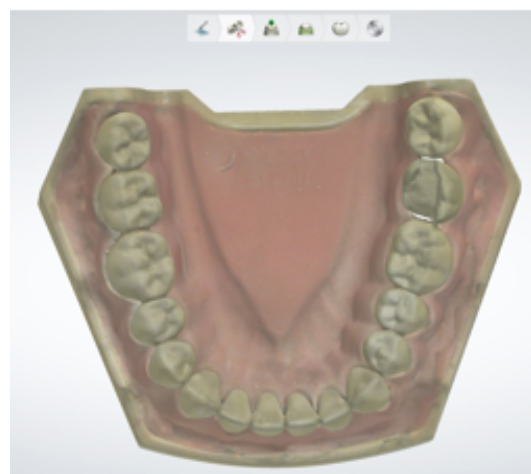

Fig. 2. Model scan

(S2).

(Wieland Dental + Technik GmbH \& Co. KG, Pforzheim, Germany). The details of this stage of the study are summarized in the Study design section below (Flowchart 1). The software that was used for the design was DentalManager Dental System ${ }^{\mathrm{TM}} 2018$ Premium (3Shape, Copenhagen, Denmark).

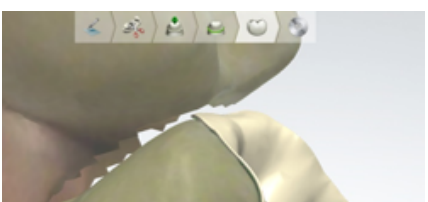

Fig. 4. Virtual inlay on the model scan.

The Vita Enamic ${ }^{\circledR}$ hybrid ceramic and the IPS Empress CAD ceramic haven been particularly chosen due to their lack of subsequent sintering requirement after milling.

The following is a short technical description of the materials used:

-Blocks of glass ceramic in a resin-interpenetrating matrix, shaded 1M1-HT (Enamic ${ }^{\circledR}$, Vita, Germany). This is composed of a dual network: a feldspathic ceramic network ( $86 \%$ by weight $/ 75 \%$ by volume) and a polymer network ( $14 \%$ by weight/25\% by volume). The specific composition of the ceramic part is $58 \%$ to $63 \% \mathrm{SiO}_{2}, 20 \%$ to $23 \% \mathrm{Al}_{2} \mathrm{O}, 9 \%$ to $11 \% \mathrm{Na}_{2} \mathrm{O}, 4 \%$ to $6 \% \mathrm{~K}, \mathrm{O}, 0.5 \%$ to $2 \%$ $\mathrm{B}_{2} \mathrm{O}_{3}$, less than $1 \%$ of $\mathrm{Zr}, \mathrm{O}$ and $\mathrm{CaO}$. The polymer network is composed of urethane dimethacrylate (UDMA) and triethylene glycol dimethacrylate (TEGDMA). The manufacturer refers to this as a hybrid ceramic [15].

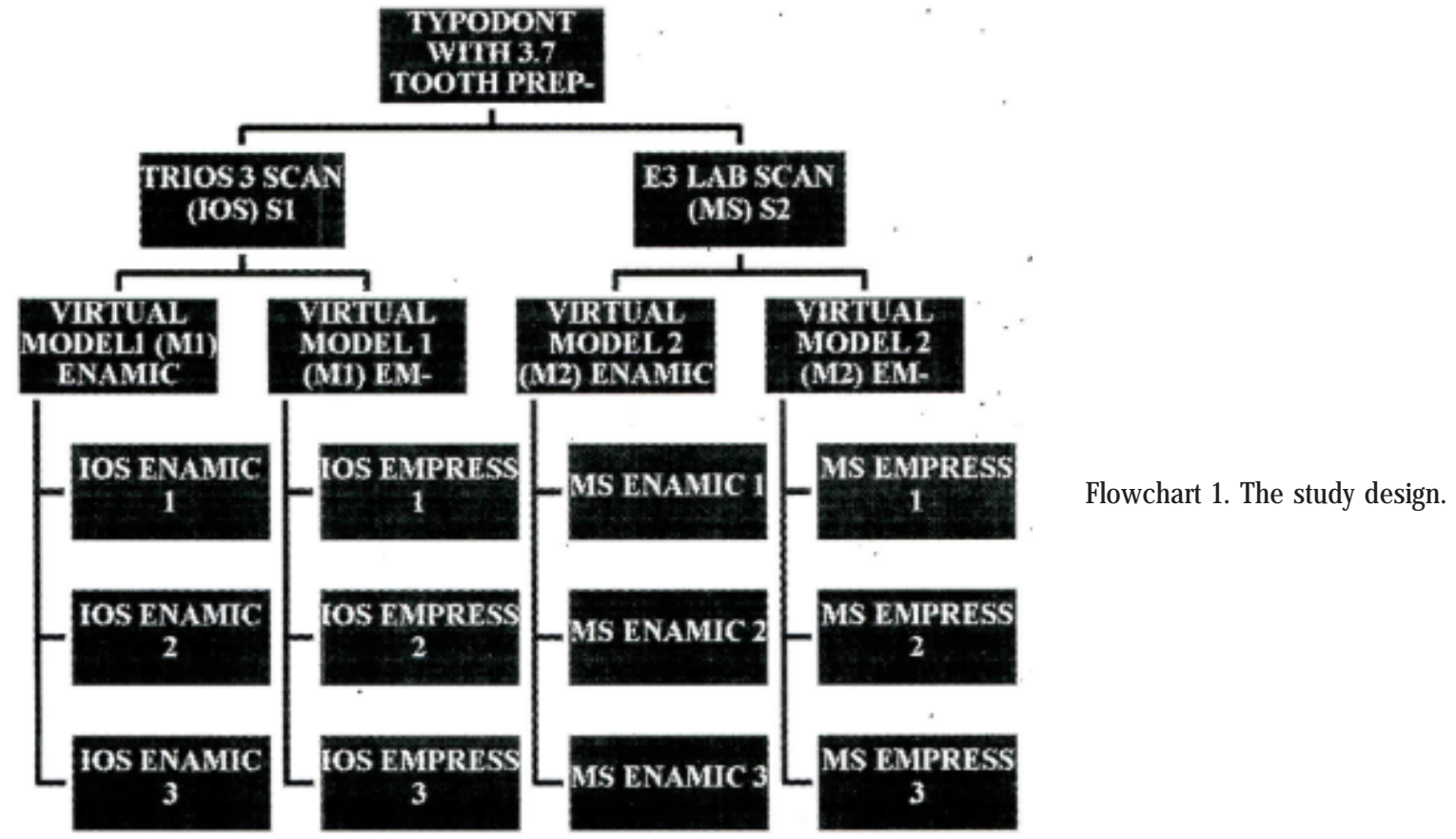

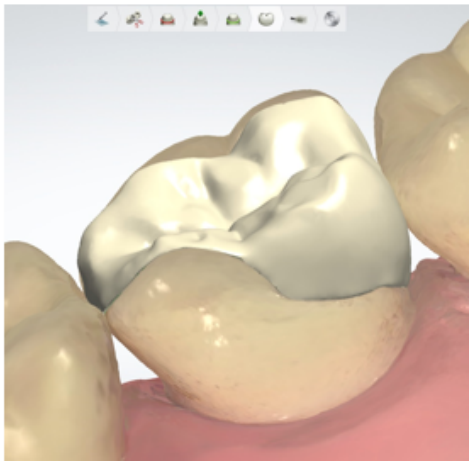

Fig. 3. Virtual inlay on the intraoral scan
-Blocks of glass ceramic shaded A1-HT (IPS Empress CAD, Ivoclar Vivadent, Liechtenstein), with the following standard composition (in weight \%) : $\mathrm{SiO}_{2}: 60.0-65.0, \mathrm{Al}_{2} \mathrm{O}_{3}$ : 16.0 - 20.0, $\mathrm{K}_{2} \mathrm{O}: 10.0$ - 14.0, $\mathrm{Na}_{2} \mathrm{O}: 3.5$ - 6.5, Other oxides: 0.5 - 7.0, Pigments: $0.2-1.0$. Other properties: Flexural strength (biaxial): $160 \mathrm{MPa}$, Chemical solubility < $100 \mu \mathrm{g} /$ $\mathrm{Cm}^{2}$, Coefficient of thermal expansion $\left(100-500{ }^{\circ} \mathrm{C}\right): 17.5$ $\pm 0.5 \mu \mathrm{m} /\left(\mathrm{m}^{\prime \prime \prime} \mathrm{K}\right)$, Transformation temperature: $625 \pm 20$ ${ }^{\circ} \mathrm{C}$.

The Frasaco Typodont 3.7 tooth was removed from the phantom arch and 4 distinct areas were marked on each of the prepared surfaces (mesial, distal, occlusal and lingual) using a black permanent marker. Each of the 12 


\begin{tabular}{|c|c|c|c|c|c|}
\hline & & Mesial & Distal & Occlusal & Lingual \\
\hline \multirow{6}{*}{ Enamic } & IOS 1 & 223.51 & 134.92 & 111.61 & 21.86 \\
\hline & $\operatorname{IOS} 2$ & 106.95 & 98.50 & 144.54 & 127.93 \\
\hline & $\operatorname{IOS} 3$ & 2.33 & 109.57 & 138.42 & 136.38 \\
\hline & MS 1 & 58.28 & 71.40 & 182.13 & 111.90 \\
\hline & MS 2 & 22.15 & 113.65 & 96.16 & 22.68 \\
\hline & MS 3 & 249.37 & 143.37 & 335.81 & 107.85 \\
\hline \multirow{6}{*}{ Empress CAD } & $\operatorname{IOS} 1$ & 122.97 & 57.12 & 70.81 & 151.82 \\
\hline & $\operatorname{IOS} 2$ & 122.97 & 447.86 & 57.99 & 108.40 \\
\hline & $\operatorname{IOS} 3$ & 193.31 & 144.83 & 114.23 & 70.23 \\
\hline & MS 1 & 42.84 & 18.94 & 55.95 & 28.85 \\
\hline & MS 2 & 11.95 & 91.21 & 64.53 & 58.28 \\
\hline & MS 3 & 5.83 & 83.63 & 16.03 & 88.00 \\
\hline
\end{tabular}

Table 1

RAW RESULTS OF THE MICROSCOPIC ANALYSIS OF THE MARGINAL FIT ON THE MARKED AREAS (in $\mu \mathrm{m}$ ).

inlays was individually placed on the 3.7 prepared Frasaco phantom tooth and luted with a minimal amount of cement (Temp-Bond ${ }^{\mathrm{TM}}$ Clear, KaVo Kerr, California, USA) in order to prevent dislodging due to vacuum conditions. The tooth along with the luted inlay was then inserted and fixed into the FEl Quanta Inspect FP 2017/11 (FEl, Czech Republic) scanning electron microscope and the marginal fit was evaluated on each of the 4 marked points by measuring the gap between the cervical limit of the preparation on the Frasaco tooth and the luted inlay. The entire process was carried out at 1000x magnification whenever possible.
After measuring the marginal fiton the pre-marked area, the entire tooth-preparation interface being scanned was examined at lower magnifications in order to detect whether or not other regions would display greater or lesser values of marginal adaptation (however, only discrepancies of more than $30 \mu \mathrm{m}$ were taken into consideration). If such areas were found, they were also measured and recorded using the 1000x magnification whenever possible. As a general criterion, the commonly acceptable threshold of $120 \mu \mathrm{m}$ was regarded as a reference for evaluating marginal fit values as either acceptable or not [12].

\begin{tabular}{|c|c|c|c|c|c|}
\hline & & Mesial & Distal & Occlusal & Lingual \\
\hline \multirow{6}{*}{ Enamic } & IOS 1 & $\mathrm{NF}$ & NF & NF & NF \\
\hline & IOS 2 & $\mathrm{NF}$ & 212.44 & 82.76 & NF \\
\hline & IOS 3 & 136.38 & 159.40 & 95.00 & 109.57 \\
\hline & MS 1 & 6.12 & $\mathrm{NF}$ & 329.65 & NF \\
\hline & MS 2 & $\mathrm{NF}$ & $\mathrm{NF}$ & NF & NF \\
\hline & MS 3 & $\mathrm{NF}$ & 289.53 & 554.00 & 169.15 \\
\hline \multirow{6}{*}{ Empress $\mathrm{CAD}$} & IOS 1 & 196.70 & 275.61 & NF & $\mathrm{NF}$ \\
\hline & IOS 2 & 475.89 & NF & 136.96 & NF \\
\hline & IOS 3 & $\mathrm{NF}$ & NF & $\mathrm{NF}$ & NF \\
\hline & MS 1 & 218.54 & 199.90 & $\mathrm{NF}$ & $\mathrm{NF}$ \\
\hline & MS 2 & $\mathrm{NF}$ & 157.07 & 368.00 & 160.56 \\
\hline & MS 3 & 229.54 & 177.76 & 174.55 & NF \\
\hline
\end{tabular}

Table 2

RAW RESULTS OF THE MICROSCOPIC ANALYSIS OF THE MARGINAL FIT ON AREAS FOUND TO BE DISCREPANT COMPARED TO THE VALUE RECORDED ON THE MARKED AREA (in $\mu \mathrm{m}$ ). 


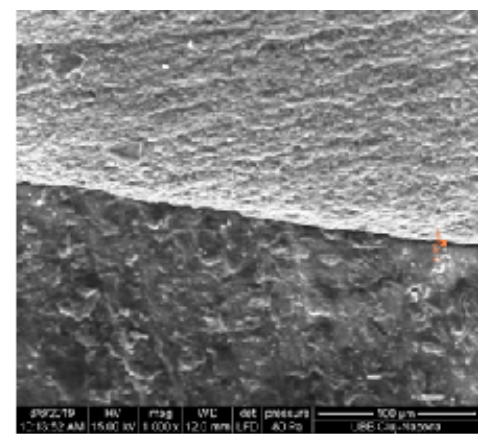

Fig. 5. IOS Enamic (mesial)- $2.33 \mu \mathrm{m}$

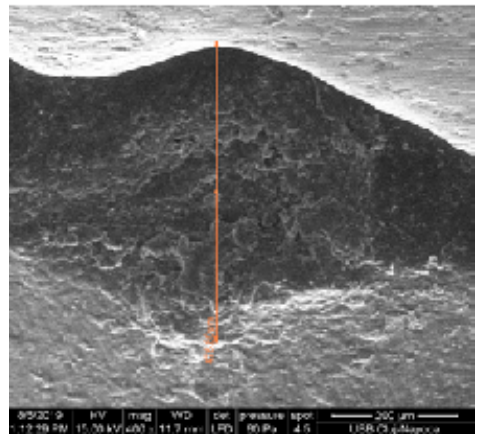

Fig. 6. IOS Empress CAD (mesial)- $475.89 \mu \mathrm{m}$ (not on the marked area).

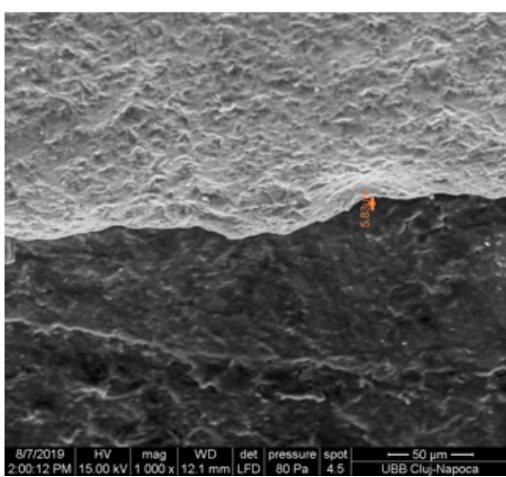

Fig. 7. MS Empress CAD (mesial) $-5.83 \mu \mathrm{m}$.

Table 3

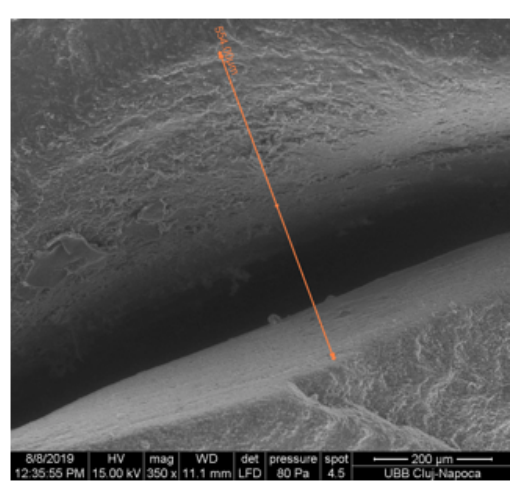

Fig. 8. MS Enamic (occlusal) - $554.00 \mu \mathrm{m}$ (not on the marked area).

MARGINAL FIT: MEAN AND STANDARD DEVIATION ON EACH SURFACE ACCORDING TO MATERIAL AND TO THE SCANNING METHOD USED. MARKED IN RED ARE THE MEAN VALUES ABOVE $120 \mu \mathrm{m}$ (I.E. CLINICALLY ACCEPTABLE THRESHOLD) AND IN GREEN THE ONES BELOW $100 \mu \mathrm{m}$

\begin{tabular}{|l|c|c|c|c|c|c|c|c|}
\hline Material & $\begin{array}{c}\text { Mean fit - } \\
\text { Mesial }\end{array}$ & $\begin{array}{c}\text { St. dev. - } \\
\text { Mesial }\end{array}$ & $\begin{array}{c}\text { Mean fit - } \\
\text { Distal }\end{array}$ & $\begin{array}{c}\text { St. dev. - } \\
\text { Distal }\end{array}$ & $\begin{array}{c}\text { Mean fit - } \\
\text { Occlusal }\end{array}$ & $\begin{array}{c}\text { St. dev. - } \\
\text { Occlusal }\end{array}$ & $\begin{array}{c}\text { Mean fit - } \\
\text { Lingual }\end{array}$ & $\begin{array}{c}\text { St. dev. - } \\
\text { Lingual }\end{array}$ \\
\hline Enamic & 110.43 & 95.13 & 111.90 & 23.62 & 168.11 & 79.71 & 88.10 & 47.51 \\
\hline $\begin{array}{l}\text { Empress } \\
\text { CAD }\end{array}$ & 83.31 & 68.29 & 140.60 & 142.53 & 72.70 & 21.41 & 84.26 & 38.95 \\
\hline Method & $\begin{array}{c}\text { Mean fit - } \\
\text { Mesial }\end{array}$ & $\begin{array}{c}\text { St. devi- } \\
\text { Mesial }\end{array}$ & $\begin{array}{c}\text { Mean fit - } \\
\text { Distal }\end{array}$ & $\begin{array}{c}\text { St. dev. - } \\
\text { Distal }\end{array}$ & $\begin{array}{c}\text { Mean fit - } \\
\text { Occlusal }\end{array}$ & $\begin{array}{c}\text { St. dev. - } \\
\text { Occlusal }\end{array}$ & $\begin{array}{c}\text { Mean fit - } \\
\text { Lingual }\end{array}$ & $\begin{array}{c}\text { St. dev. - } \\
\text { Lingual }\end{array}$ \\
\hline IOS & 128.67 & 70.32 & 165.47 & 129.39 & 106.27 & 32,09 & 102.77 & 44.36 \\
\hline MS & 65.07 & 84.34 & 84.80 & 35.86 & 146.92 & 104.46 & 69.59 & 36.78 \\
\hline
\end{tabular}

\section{Results and discussions}

The raw results of the measurements carried out on the marked areas and expressed in um are shown in Table 1.

The raw values that were significantly greater/lesser (i.e. with a minimum of $30 \mu \mathrm{m}$ discrepancy) than those obtained when measuring on the marked spot of the Frasaco tooth are displayed in Table 2. NF was noted when no such value was found.

Regarding the scanning methods, for intraoral scanning (i.e. when we used the TRIOS 3 intraoral scanner to scan the Typodont) the best marginal fit value was obtained in the case of the Enamic hybrid ceramic on the mesial surface (2.33 microns) (fig. 5), while the worst was in case of the Empress CAD ceramic on the mesial surface (475.89 microns), but not on the marked area (fig. 6). For model scanning, the best marginal fit was obtained for the Empress ceramic also on the mesial surface (5.83 microns) -Fig. 7, and the worstfit was for the Enamic hybrid ceramic inlay on the occlusal surface butnot on the marked area (554.00 microns) (fig. 8), an extremely high value, the highest recorded in this study.
Regarding the materials, for the Enamic inlay series, the best value found was on the mesial surface at intraoral scanning (2.33 microns) -Fig. 5, and the worst value on the occlusal surface on model scanning (554.00 microns) figure 8 . In the case of the Empress inlays, the best value found was with intraoral scanning on the mesial surface (5.83 microns)(fig. 7), and the worst at intraoral scaning on the distal surface (475.89 microns)(fig. 6).

Additionally, as can be seen in Table 1, almost all measurements showed scattered values.

Concerning the scanning method, model scanning seemed to be better than intraoral scanning, displaying a mean marginal fit value of $89.77 \mu \mathrm{m}$ and a standard deviation of $79.62 \mu \mathrm{m}$, meanwhile intraoral scanning only reached a mean of $125.79 \mu \mathrm{m}$ and a standard deviation of $82.43 \mu \mathrm{m}$.

The purpose of this study was to evaluate the effect of using two scanner types and two different materials (Vita Enamic ${ }^{\circledR}$, Vita, Germany, and IPS Empress CAD, Ivoclar Vivadent, Liechtenstein) on the marginal fit of inlays, therefore obtaining the possibility to assess clinical implications. 
Vita Enamic ${ }^{\circledR}$ is the first hybrid dental ceramic in the world with a dual-network structure, that combines the positive characteristics of a ceramic and a composite material. Vita Enamic ${ }^{\circledR}$ 's abrasion properties are similar to enamel, thus it has been reported that its protection of antagonist teeth is greater and a stronger adhesion with the self-adhesive dual-cure resin cement can be achieved due to its composite-like structure. The microstructural analyses showed a hybrid material composed of interconnected networks: a dominant ceramic and a polymer-based matrix [16-18].

IPS Empress CAD is a leucite-reinforced feldspathic ceramic indicated for the fabrication of inlays, onlays, veneers, endocrowns, anterior/posterior partial or full crowns. Monochrome IPS Empress CAD blocks have a bending resistance of $160 \mathrm{MPa}$; it shows outstanding esthetic properties, being available in a variety of shades from $A$ to $D$, as well as in shades for whitened teeth. These blocks can be HT (high translucency), LT (low translucency) or MO (medium opacity), indicated for masking colored teeth. Polychromatic IPS Empress CAD multi-blocks have both a chameleon effect, as well as a fluorescence similar to neighboring dental structures [19].

Ceramic inlays have many advantages, including great esthetic properties, requirement of less tooth preparation and greater preservation of healthy tooth structures. The clinical process of placing inlays has become more efficient and convenient with the development of CAD/CAM systems [20].

In 2016, Kuhr et al. concluded that digital impression models are similar to conventional models in most anatomical areas, except in secondary areas such as grooves and pits, where gypsum casts can prove to be more accurate [15].

Marginal discrepancy values for direct and indirect inlays were found to be $91.88 \mathrm{im}$ and $170.29 \mathrm{im}$ respectively. Marginal discrepancy values ranging from 48 to 219 im have been reported for various indirect composite and ceramic inlays [21, 22].

Mean marginal discrepancies of inlay restorations found in literature were $34.23 \mathrm{im}$ for IPS Empress CAD and 33.77 $\mu \mathrm{m}$ for Lava ${ }^{\mathrm{TM}}$ Ultimate (3M, Minneapolis, USA) [23].

Some other studies showed that the overall mean marginal gap value and its standard deviation were 53.45 $\mu \mathrm{m} \pm 30.52 \mu \mathrm{m}$. When comparing scanners, the minimum mean value $(40.04 \mu \mathrm{m} \pm 18.90 \mu \mathrm{m})$ was recorded on PlanScan ${ }^{8}$ (Planmeca Oy, Helsinki, Finland), followed by 3D PROGRESS Plus (Aniwaa, Singapore) - $40.20 \mu \mathrm{m} \pm$ $21.91 \mu \mathrm{m}$, True Definition Scanner (3M, Minneapolis, USA) $-40.82 \mu \mathrm{m} \pm 26.19 \mu \mathrm{m}$, the CS 3500 scanner (Carestream Dental, Georgia, USA) $-54.82 \mu \mathrm{m} \pm 28.86 \mu \mathrm{m}$, the CS 3600 scanner (Carestream Dental, Georgia, USA) - $59.67 \mu \mathrm{m} \pm$ $28.72 \mu \mathrm{m}$, CEREC Omnicam (Dentsply Sirona, Pennsylvania, USA) - $61.57 \mu \mathrm{m} \pm 38.59 \mu \mathrm{m}$, and the DW IO scanner (Dental Wings Inc., Montreal, Canada) - $62.49 \mu \mathrm{m} \pm 31.54$ $\mu \mathrm{m}$. The highest mean value ( $67.95 \mu \mathrm{m} \pm 30.41 \mu \mathrm{m})$ was recorded on TRIOS 3 (3Shape, Copenhagen, Denmark) [12]. Our study, even if consisting of a smal lot (only 12 samples), showed an even greater discrepancy, namely a mean value of $108.17 \mu \mathrm{m}$ and a standard deviation of 81.79 $\mu \mathrm{m}$ on the marked measuring area, thus exhibiting values that exceed the clinically acceptable threshold of $120 \mu \mathrm{m}$ [12].

We have also found studies that have demonstrated a higher marginal accuracy of restorations derived from an intraoral scanner in comparison to conventional impressions [24].
Inlays generated from conventional wax and resin models tend to show higher marginal discrepancies than conventional digital and full digital patterns. Wax and resin materials yield similar marginal fit accuracies, regardless of impression/manufacturing technique. Better internal fit was shown in wax when compared to resin patterns, irrespective of technique [25].

The use of an intraoral scanner for digital impressions may be a viable alternative to analog techniques. Ferrini et al. concluded that even though PlanScan ${ }^{\circledR}, 3 D$ PROGRESS Plus and True Definition Scanner may have showed the best performances, all intraoral scanners tested could provide clinically encouraging results, especially in terms of marginal accuracy, since mean marginal gap values were all within the clinically acceptable threshold of 120 $\mu \mathrm{m}$ [12]. How ever, regarding our study, marginal fit values above this threshold were 36 out of 71 (taking both marked and non-marked areas into account), which represented a $50.7 \%$ ratio that was considerably high.

Furthermore, our data was not very conclusive. For example, when analyzing the marginal fit of the materials, Empress CAD displayed the lowest mean value $(96.20 \mu \mathrm{m})$, but it also presented the highest discrepancies recorded in this study $(554.00 \mu \mathrm{m}$ on the occlusal aspect and 475.89 $\mu \mathrm{m}$ on the mesial surface - however, both recorded on non-marked areas of the 3.7 Typodont tooth).

\section{Conclusions}

The study concluded that the type of scanning may influence the marginal fit, the best results being obtained this time with the model (laboratory) scanner. The ceramic ( IPS Empress CAD) seemed to perform better than the hybrid ceramic ( Vita Enamic), possibly due to its lack in a polymer-based matrix. From a periodontal point of view, this would greatly influence gingival health when preparations are necessary at the level of or even below the gingival margin. When combining materials and scanning methods, the best result we obtained this time was between the ceramic (Empress CAD) and the model (laboratory) scanner (E3 Lab Scanner, 3Shape, Copenhagen, Denmark)

Some of the marginal gaps we found were greater than 120 microns (some of which even close to the five-fold of this value), which is considered to be the clinically acceptable maximum threshold [12], and many values found for the same virtual inlay model were greatly scattered. This fact raises new questions: What may be the cause of discrepant marginal adaptations when milling the same prosthetic design multiple times for the same preparation? Whatfactors need to be further analyzed when taking marginal fit into account?

This follow-up study is, however, limited due to the small sample lot that we had at our disposal, thus future studies are recommended on a larger amount of samples in order to obtain statistically significant results.

\section{References}

1.CARVALHO, T.F., LIMA, J .F.M., DE MATOS, J .D.M., LOPES, G.R.S., DE VASCONCELOS, J.E.L., ZOGHEIB, L.V., DE CASTRO, D.S.M., Int. J. Odontostomat., 12, 2018, p. 368

2.LINS, L., BEMFICA, V., QUEIROZ, C., CANABARRO, A., J. Prosthet. Dent., 113, 2015, p. 205

3.BANKOGLU GUNGOR, M., DOĐAN, A., TURHAN BAL, B., KARAKOCA NEMLI, S., Acta Odontol. Turc., 35, 2018, p. 1

4.J OKSTAD, A., Dental Materials, 32, 2016, p. 11

5.YILDIZ, C., VANLIOGLU, B.A., EVREN, B., ULUDAMAR, A., OZKAN, Y.K., Dent. Mater. J., 32, 2013, p. 42 
6.TAMAC, E., TOKSAVUL, S., TOMAN, M., J. Prosthet. Dent., 112, 2014, p. 909

7. BACIU, S., FLOREA, A., MANOLE, M., ALB, C., PIRTE, A., RUSU, LC., SINESCU, C., Mat. Plast., 52, no. 2, 2015, p. 214

8.BACIU, S., FLOREA, A., MANOLE, M., ROMAN, A., ALB, S., ALB, C., PIRTE, A., SINESCU, C., Mat. Plast., 52, no. 3, 2015, p. 393

9.BUDURU, S., MESAROS, A., CULCITCHI, C., MOLDOVAN, M., PRODAN, D., SZUHANEK, C., Mat. Plast., 55, no. 3, 2018, p. 376

10.RATIU, C., ALMASI, A., PORUMB, A., MUNTEAN, A., Mat. Plast. 54, no. 1,2017, p. 56

11.J ODA, T., ZARONE, F., FERRARI, M., BMC Oral Health, 17, 2017, p. 124

12.FERRINI, F., SANNINO, G., CHIOLA, C., CAPPARÉ, P., GASTALDI, G., GHERLONE, E.F., Int. J. Environ. Res. Public Health, 16, 2019, p. 544 13.SANDOVAL, M.J ., ROCCA, G.T., KREJ CI, I., MANDIKOS, M., DIETSCHI, D., Clin. Oral Investig., 19, 2015, p. 2167

14.CHAN, D.C., CHUNG, A.K., HAINES, J., YAU, E.H., KUO, C.C., Oper Dent., 36, 2011, p. 486

15. KUHR, F., SCHMIDT, A., REHMANN, P., WSSTMANN, B., J. Dent., 55, 2016, p. 68
16.DELLA BONA, A., CORAZZA, P.H., ZHANG, Y., Dental Materials, 30, 2014, p. 564

17.ALBERO, A., PASCUAL, A., CAMPS, I., BENITEZ, M.G., J . of Clin. and Experiment Dentistry, 7, 2015, p. 495

18.*** VITA ENAMIC, Technical and scientific documentation, Date of issue 08.16, p.4, Available on Internet: https://cdn.vivarep.com/contrib/ vivarep/media/pdf/4_4642_ENAMIC Technical and Scientific 2017083020574457 8.pdf. [cited 2019.08.02]

19.***IPS Empress CAD monolithic solutions. Instructions for use.IvoclarVivadent technical. Available on Internet: https:// www.ivoclarvivadent.com/en/p/all/products/all-ceramics/ips-empresssystem-technicians/ips-empress-cad. [cited 2019.08.01]

20.LIU, X., FOK, A., LI, H., Dental Materials, 30, 2014, p. 327

21.GEMALMAZ, D., KUKRER, D., J. Oral Rehabil., 33, 2006, p. 436

22.TURK, A.G., SABUNCU, M., UNAL, S., ONAL, B., ULUSOY, M., J. Appl. Oral. Sci., 2016, p. 383

23.OZ, F.D., BOLAY, S., Int. J. Dent., 2018, p. 1

24.NG, J., RUSE, D., WYATT, C., J. of Prosthet. Dent., 112, 2014, p. 555 25.HOMSEY, F.R., OZCAN, M., KHOURY, M., MAJZOUB, Z.A.C., J. of Prosthet. Dent., 120, 2018, p. 530

$\overline{\text { Manuscript received: } 16.07 .2019}$ 